Article

\title{
Green Purchasing Behaviour towards Compostable Coffee Pods
}

\author{
Rebecca Visser and Siphiwe Dlamini *(1) \\ School of Management Studies, University of Cape Town, Cape Town 7700, South Africa; Vssreb001@myuct.ac.za \\ * Correspondence: Siphiwe.dlamini@uct.ac.za
}

Citation: Visser, R.; Dlamini, S.

Green Purchasing Behaviour towards Compostable Coffee Pods.

Sustainability 2021, 13, 6558

https: / doi.org/10.3390/su13126558

Academic Editor: Sara

González García

Received: 9 March 2021

Accepted: 7 June 2021

Published: 8 June 2021

Publisher's Note: MDPI stays neutral with regard to jurisdictional claims in published maps and institutional affiliations.

Copyright: (c) 2021 by the authors. Licensee MDPI, Basel, Switzerland. This article is an open access article distributed under the terms and conditions of the Creative Commons Attribution (CC BY) license (https:// creativecommons.org/licenses/by/ $4.0 /)$.

\begin{abstract}
The field of green marketing and purchase behaviour has been growing in the last couple of years; consequently, there is a need to understand this behaviour among coffee consumers. Coffee is considered one of the widely consumed beverages in the world. There is heightened consciousness towards the environmental awareness of the product of compostable coffee pods. This study aims to fill this gap by providing a holistic conceptual framework to determine which factors influence green purchasing behaviour with regard to compostable coffee pods and whether gender and income have an impact. To achieve this aim, structural equation modelling (SEM) will be utilised on SmartPLS from data collected from 133 South African coffee pod consumers using an online survey. The findings indicated that interpersonal influence and altruistic values have a significant positive influence on environmental attitude and that environmental attitude has a significant positive effect on green purchasing behaviour. However, it was found that no significant relationship was observed between environmental knowledge and environmental attitude. Regarding the influence of gender and income as mediators, no influence was found in the relationship between environmental attitude and green purchasing behaviour. However, income level partially mediates this relationship. The results will provide practical solutions for marketers and policymakers.
\end{abstract}

Keywords: green purchasing behaviour; compostable coffee pods; environmental attitude; coffee pods; circular economy

\section{Introduction}

Coffee is the most widely known and popular beverage on a global scale, with more than 500 billion cups of coffee consumed annually [1]. The international coffee pod market has shown rapid growth due to consumers' inclinations towards innovation, convenience, and lifestyle changes, which have, in turn, driven the global adoption of coffee pod machines [2]. South Africans adapt to global trends, this being seen in a $2 \%$ annual increase in coffee consumption as well as a surge in the purchase of complementary items that are linked with premium coffee, namely coffee machines [3]. There has also been a change in the South African profile of the coffee consumer, shifting towards a young, upwardly mobile market. In addition to this, a South African coffee culture has been developing that can be described as a 'market experiencing sophistication' [3].

While growing coffee can add to economic pursuits, it is essential that the coffee industry also contemplates its influence on the environment from agriculture to consumption to ensure sustainability [4]. Sustainability practices in green purchasing behaviour are developing and show that consumers are prioritising them [5]. Consumers' purchase decisions are influenced by this growing awareness and predisposition towards sustainability [6,7]. Notwithstanding sustainable production, other practices that steer sustainable consumption behaviour have gained attention as feasible sustainable development strategies $[5,8]$. Most studies provide two perspectives to sustainability: the production or consumption side. Most studies offer a single-side environmental perspective [9]; sustainability issues expand beyond green consumption [10]. However, the shift towards sustainability looks at the roles of consumers, since, in developed markets, consumption drives much of the environmental issues [11]. Consequently, awareness about the interface between a consumers' 
level of sustainability interest and buying behaviour in different consumption patterns is lacking [12]. Hence, there is a need to look for other factors that can explain the direct link between consumer awareness about environmental knowledge, environmental attitude, and pro-environmental behaviour (6).

However, current consumers are developing a heightened concern and awareness of their social responsibilities as well as the direct impacts that their purchasing behaviour has on the environment [2]. The need for environmentally sensitive or 'green' behaviour has come to the forefront, and there is an increased pressure for businesses to act in socially ethical and responsible ways as well as to comply with pro-environmental practices [13]. With regard to the consumption of coffee pods, waste has now become a critical issue $[13,14]$.

Existing literature has explored green purchasing behaviour regarding emerging markets and economies $[15,16]$. In addition, consumer research has been conducted in relation to sustainable expenditure and packaging, but as this was undertaken in the Global North and therefore from the developed market and economic perspective, these findings cannot be generalised to include developing countries in the Global South [13].

Prior research has shown that various psychographic variables aid in the explanation of green purchasing behaviour and are closely related to this construct in the context of developed economies. These are interpersonal influence, environmental concern, altruism, skepticism, perceived environmental responsibility, environmental knowledge, and environmental attitude [14]. There has also been research that has examined consumer behaviour, consumption, and values in relation to the coffee pod market and has used the green awareness of consumers to promote a circular economic waste-to-resource management in the coffee pod industry [2]. However, there is limited research that has focused on sustainable expenditure patterns and green purchasing behaviour in South Africa as well as the effect of demographic variables on green purchasing behaviour [13]. There has also been little exploration of South African consumer behaviour with regard to the consideration and purchase of compostable coffee pods.

Due to the lack of advances in the coffee roasting industry, very few countries are green coffee importers (1). The advent of coffee capsules has upset the product market. Undeniably, coffee pods require space, demanding more packaging requirements including materials such as aluminium and plastic than conventional coffee packages, even though the amplified consumption of coffee pods has created a new problem, that is, they are discarded after consuming the coffee $(1,2)$. This problem has created environmental stewardship from a consumer perspective; as a result, coffee consumption and behaviour are changing (2,3). In other words, the green behaviour of coffee consumers is significant for a thriving coffee industry and a country's sustainability goals (2). Packaging and labelling perform an important role in the environment and thus environmentally friendly or sustainable offers governments, companies, and policymakers the possibility of developing a green position (13).

A study by [17] revealed that, while $67 \%$ of consumers hold a favourable environmental attitude, only $4 \%$ of these participated in pro-environmental and green purchases. The exploration of green purchasing behaviour has revealed a 'gap' between these expressed pro-environmental attitudes and individuals' purchasing behaviour [14]. This incongruity is known as the 'attitude-behaviour gap', and it is therefore crucial to explore this discrepancy in order to address this issue [14].

Research by [14] has indicated that certain attitudinal variables are useful in explaining the construct of green purchasing behaviour, namely pro-environmental attitude, interpersonal influence, altruism, and environmental knowledge. However, as few studies have researched the influence of these factors on green purchasing behaviour with regard to compostable coffee pods, this study has further examined the factors that influence the research construct. Furthermore, little is known about South African green marketing and consumer behaviour with regard to the consideration and purchase of compostable coffee pods.

The current study contributes to the current literature in the following ways: 
- It enhances the limited literature on sustainable green consumption in the South African context by analysing the influence of environmental attitude on South African consumer altruism, interpersonal influence, and environmental knowledge on green purchasing behaviour for compostable coffee pods

- Analysis of this study suggests key insights into the lack of gender-based consciousness and income impact for marketers and researchers to optimise the influence of factors studied in the study.

Consequently, the aim of this study was to answer the following research question:

Which factors influence consumers' green purchasing behaviour towards compostable coffee pods?

To answer this research question, we tested a unique conceptual model to investigate how consumers' altruism, interpersonal influence, and environmental knowledge on green purchasing behaviour for compostable coffee pods is mediated by environmental attitude. Furthermore, we tested for the differences between genders (female and male consumers) related to the above-stated variables. In addition, we explore the role of income as a driver of affordability and purchase behaviour.

\section{Literature Review}

\subsection{The Circular Economy}

The idea of a circular economy is rapidly becoming a global concept and approach. This is due to the extensive literature that reveals an imperative case for shifting away from the 'take, use, dispose' mentality of resources adopted by business and industrial processes and moving towards regeneration and resource renewal [18-20]. This is about maximising long-term material value whilst minimising waste that takes place in the product and business supply chain [2]. The concept of the circular economy has been associated with replacing the process of land filling with alternative waste management solutions such as composting and recovery resources from waste [18].

The 2015 United Nations General Assembly saw an intensified initiative to act on these concepts and to divert attention to business resource value, the flow of materials, and waste management [21]. This approach also requires design innovation as well as the removal of inefficiencies within the production of these products and services. The circular economy framework focuses on four key areas, namely production and consumption, waste management, secondary raw materials, and competitiveness and innovation [2]. It has been applied to regional and national governments across Asia and Europe to direct their sustainable development [19].

The study by [21] indicates that a critical consideration of the easy-to-access products/services and motivation of public participation needs to take place when employing the framework of the circular economy and implementing it at a micro level. Public participation and the promotion of consumers' responsibility are crucial when implementing and increasing the purchase and adoption of more sustainable products such as compostable coffee pods [20].

\subsubsection{Environmental Impacts of Coffee Pods}

Waste is a critical issue surrounding the coffee pod industry, which is now searching for an alternative to combat this waste inefficiency as well as increase resource productivity and effectiveness [21]. Results from a study by [21] revealed that the recyclable aluminum format of a coffee pod has the largest probable negative environmental effects across nine impact categories, namely ozone depletion, global warming, smog, acidification, eutrophication, carcinogenic, non-carcinogenic, respiratory effects, and ecotoxicity. The plastic and aluminum composite structure of a generic pod is often unable to be recycled in most municipal and industrial recycling plants due to the challenges posed by the pod being a proprietary mixture of different plastics [22]. This non-recyclable packaging property of coffee pods may act as a hindrance to the growth of the global market for coffee pods [22]. Although there are recyclable pods available in the market, they have been 
scrutinised and criticised for the low rate at which they are being recycled [23]. Tones of coffee pods are ending up in landfills or being incinerated on a global scale [21].

Even considering this criticism, there is still a drive towards increasing profitability in the global marketing and sales of coffee pods rather than a focus on responsible production [2]. The current use by the coffee production chain of environmentally detrimental packaging has raised questions amongst consumers regarding the ethics of the supply chain as well as the production of coffee. This offers the industry an opportunity to move towards a more circular business model that reduces the environmental impact of the pod-style coffee system by producing and using biobased polymers that are biodegradable and hence compostable $[2,23]$.

\subsubsection{Compostable Coffee Pods}

Consumers are now making the link between coffee pods and the world-wide waste problem. However, there is a lot of confusion in the market with regard to the structural differences between biodegradable pods and recyclable pods, which poses a challenge to waste managers and municipalities due to the allocation of responsibility with regard to waste collection and separation [23]. Companies have therefore increased the focus on compostable coffee pod options, as consumers are seeking to make a difference and are often skeptical that the recyclable options may not provide the sought-after outcome from a pro-environmental perspective [23]. The compostable pod has minimal greenhouse gas emissions and reduces waste generation in landfills in comparison to the generic plastic and aluminum pods [21].

\subsection{Conceptual Framework and Hypothesis Development}

This study reviewed the factors that influence consumers' green purchasing behaviour towards compostable coffee pods.

Figure 1 below displays the variables that were included in this study. It presents the framework whereby interpersonal influence, altruism, environmental knowledge, and environmental attitude are the independent variables. The demographic factors of income level and gender are the mediating variables, and green purchasing behaviour is the dependent variable. This framework, adapted from studies conducted by [14,24], was used to identify whether there was a relationship between the variables.

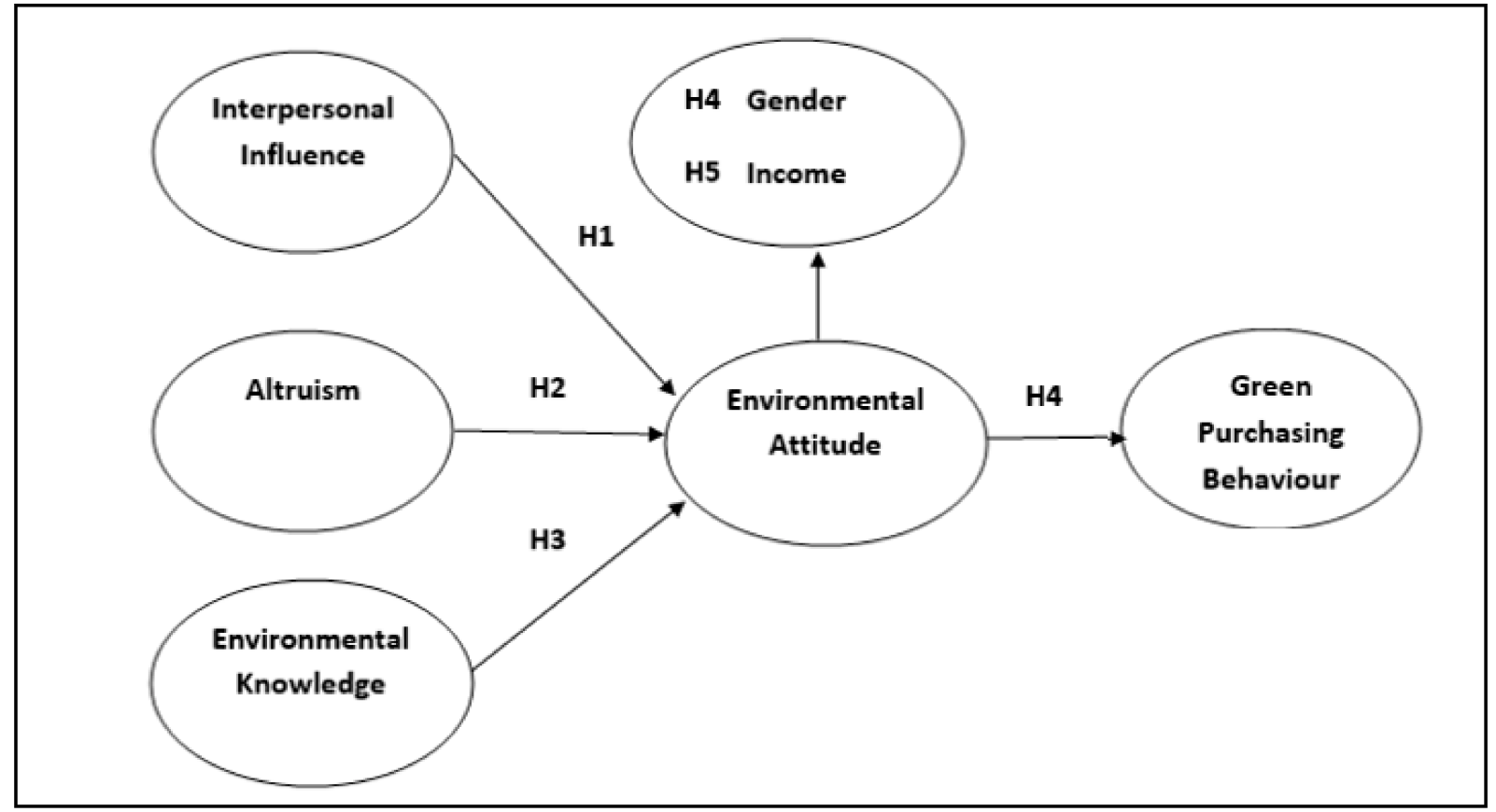

Figure 1. Conceptual framework. 
The proposed relationships that were tested with relevant hypotheses are indicated as arrows between the respective variables. This allowed the researcher to draw valid conclusions based on the factors that influence green purchasing behaviour with regard to compostable coffee pods.

\subsubsection{Interpersonal influence}

Interpersonal influence has been defined as the degree of others' influence on an individual's beliefs and values as well as their behaviours and attitudes; it is a result of that individual's willingness to accept the mandates of the social group [25]. Reference [26] suggested that interpersonal influence is an attitudinal variable that consists of behaving in a way that influences, convinces, or persuades other individuals; they revealed that interpersonal influence is a predictor of an individual's attitude and behaviour.

Interpersonal influence is what motivates, as well as forms, human beliefs and attitudes [14]. Reference [26] showed that attitudes and beliefs towards environmental products are influenced by social norms and peer groups and that consumers are exposed to and educated about environmental products through social groups such as family or peers, who thus play a vital role in influencing these respective consumers' purchasing decisions. A study by [27] suggested that people are also often motivated to buy green products to portray a positive image of themselves.

In summary, consumers' attitudes towards green products are influenced by social norms and groups [26-28]. They adopt green products not only because of their concern for the environment, but also due to social pressure [28]. The authors of [26] have extensively studied the effect of interpersonal influence on environmental attitude, while [28] observed that interpersonal influence is positively associated with environmental attitude. Therefore, the study poses the following hypothesis:

Hypothesis 1 (H1): Interpersonal influence has a significant positive effect on consumers' environmental attitude with regard to compostable coffee pods.

\subsubsection{Altruism}

Altruism is defined as the state in which a person takes responsibility for another through his/her actions without expectation of any form of benefit or advantage [14]. Research by [7] revealed that altruism is an important determinant of various pro-environmental attributes. They also showed that altruism is a positive predictor of a pro-environmental attitude and that someone who has a strong altruism weighting is more likely to have a positive environmental attitude [7]. An earlier study by [29] also revealed that people with a high altruistic weighting are more likely to possess a positive environmental attitude.

Reference [7] also highlighted the significance of altruism in determining purchase intentions of consumers in developing nations. A study by [30] suggests that green purchasing behaviour becomes more probable when an individual displays altruistic value. Displayed through an awareness of harmful consequences to others, an altruistic individual takes responsibility for changing the offending condition, in this case, the detrimental environmental condition [30].

Studies investigating the effects of pro-environmental and altruistic factors often find important influences on the green purchasing behaviour of environmentally and socially conscious products [31]. As noted, the study by [30] found that altruism has a significant positive influence on the intention to buy green products. Although the link between sustainable products and altruistic attitudes appears to be a direct one, only a few studies have specifically included these factors in research on sustainable food consumption and green purchasing behaviour [31].

This study focused on the influence of altruism on environmental attitude with regard to compostable coffee pods. Following the literature reviewed above, this study anticipated a significant impact of altruism on environmental attitude. It therefore poses the following hypothesis: 
Hypothesis 2 (H2): Altruistic values have a significant positive effect on consumers' environmental attitude with regard to compostable coffee pods.

\subsubsection{Environmental Knowledge}

The authors of [7] defined environmental knowledge as an awareness of environmental issues and the understanding of key relationships that lead to environmental impact. The authors of [14] asserted that environmental knowledge influences buying behaviour and is closely related to environmental attitude, while [32] revealed that consumers who had higher degrees of environmental knowledge simultaneously showed a positive environmental attitude, indicating a positive relationship. A study by [30] identified that when comparing individuals who were more actively engaged in environmental issues to individuals who were less engaged, the single factor that differentiated the two groups from one another was environmental knowledge of the specific issues.

Previous research has explored the relationship between environmental knowledge, attitudes, and green purchasing behaviour [33]. Reference [34] investigated environmental knowledge as an influencing factor and revealed a positive relationship with environmental attitude. However, results from previous studies that directly relate environmental knowledge to environmental attitude are inconclusive, with some studies finding a positive relationship [34,35] while others finding only a weak or no direct relationship [36,37]. As the relationship between environmental knowledge and environmental attitude needs to be further explored, this study poses the following hypothesis:

Hypothesis 3 (H3): Environmental knowledge has a significant positive effect on consumers' environmental attitude with regard to compostable coffee pods.

\subsubsection{Environmental Attitude}

Environmental attitude is described by [14] as an individual's ability to evaluate the environment's condition with a certain degree or response of favor or disfavor. Environmental attitude is known to be a determinant of pro-environmental behaviour [38]. This is shown through research by [39], which revealed that consumers who held a favourable environmental attitude were more inclined to act/behave in a pro-environmental way, which, in turn, positively influenced their green purchasing decisions.

To understand the behaviour of ecologically conscious consumers, environmental attitude has been identified as one of the primary and most important antecedent variables that determines subsequent green purchase intention and behavioural action [38-40]. Reference [41] found a strong link between green purchasing behaviour and attitude towards environment-friendly packaging in America. This research also found that consumers who have a more favourable attitude towards environmentally friendly packaging such as compostable packaging were more inclined to participate in green purchasing behaviour [31]. Reference [42] suggested that attitude towards an environmentally packaged product is an important area that requires attention in order to build consumer confidence in buying green products. However, none of the previous studies have focused on this relationship in the context of compostable coffee pods [40]. Therefore, it has been hypothesised that:

Hypothesis 4 (H4): Environmental attitude has a significant positive effect on consumers' green purchasing behaviour towards compostable coffee pods.

\subsection{Demographic Variables}

A review of earlier studies has revealed that demographic factors play a significant role in both negatively and positively influencing the green purchasing behaviour of consumers, these factors being age, gender, education level, occupation, income level, and family size $[24,43,44]$.

This study analysed gender and income level as mediating variables. A mediating variable can be described as a linking variable that changes the strength of a relationship be- 
tween a dependent and independent variable [45]. Mediation further aids the explanation of relationships between variables.

\subsubsection{Gender}

Several studies have revealed that females are more likely than males to take part in pro-environmental purchasing behaviour with regard to green products $[43,46,47]$. Gender was used as a mediating variable in the study by [43], which found that the relationship between green labelling and green purchase intentions was more significant amongst females than males. Results of research conducted by [48] also showed a significant difference between environmental attitudes of males and females, revealing that women held a more favourable environmental attitude than men. Numerous studies on environmental consumption conducted in countries in the Global North also found that women are more likely to make eco-friendly purchasing decisions than men and that women are more likely to participate in pro-green purchasing behaviour [49].

Gender differences with regard to sustainable consumption and attitudes towards the environment are not universal and are not conclusive. This was seen in research by [50], which discussed numerous studies, concluding that men show a higher level of environmental knowledge than women and act accordingly. Reference [51] refers to the differences in results as the 'gender gap'.

Due to the different findings outlined above, gender differences in green purchasing behaviour and environmental attitude need to be explored. While previous research has measured the relationships between gender and environmental attitudes and behaviour, few studies have examined the mediating role of gender on green purchasing behaviour and environmental attitude [49]. Therefore, this study poses the following hypothesis:

Hypothesis 5 (H5): The demographic variable of gender mediates the relationship between environmental attitude and green purchasing behaviour.

\subsubsection{Income Level}

A study by [52] revealed that an individual's income level is positively related to environmental sensitivity. Reference [53] showed that a positive relationship exists between income level and environmental behaviours and that individuals with higher income levels are more likely to favor environmental and green products, as they are able to bear the marginal increase in costs associated with these items. Reference [52] concurred that income level influences an individual's willingness to pay marginally higher prices. Reference [54] revealed that countries with lower incomes per capita showed a decrease in willingness to pay higher prices for environmental products.

Reference [52] also noted that while income has been used as a predictor for environmental attitude, there is an inconsistency in the results of studies on the influence of income on environmental attitude and green purchasing behaviour. The same study also emphasised the fact that the relation between the level of income and environmental concern is a critical issue in environmental economics [52].

Due to the inconsistency in results of these prior studies that examined the influence of income level on green purchasing behaviour and environmental attitude, this study explores this topic further. In addition, prior studies have examined the relationship between income, green purchasing behaviour, and environmental attitude, but few studies have investigated the effects of income level as a mediating variable between green purchasing behaviour and environmental attitude. Therefore, this study poses the following hypothesis:

Hypothesis 6 (H6): The demographic variable of income level mediates the relationship between environmental attitude and green purchasing behaviour. 


\section{Materials and Methods}

The study utilised a descriptive research design, as it made use of quantitative research methods to analyse data. As there was only one group of respondents, and data from this sample were only collected on a singular event, a single cross-sectional approach was used [45]. The research method was adapted from four related studies on the factors that influence green purchasing behaviour in developing nations with regard to coffee pods $[2,13,14,30]$.

The target population for the study was South African coffee pod consumers over the age of 18 . This choice allowed access to widespread data concerning the demographic variables of income, age, and gender as well as coffee consumption preferences. Respondents were selected based on convenience, as also employed in studies by [13,14]. However, time constraints resulted in a smaller sample size of 133 respondents being obtained.

This study utilised a structured questionnaire, designed specifically to obtain the quantitative data needed to answer the study's research question [45].

The questionnaire was administered electronically via email to the research participants, using the online survey platform Qualtrics. The questions were checked with a sample of 30 respondents, as this is the recommended sample size for a pre-test [55].

The statistical analysis software programme SPSS was used for the analysis of the data so that the researcher could run statistical tests. The inferential statistics used were mediation tests and structural equation modelling (SEM). SEM was conducted on SmartPLS, a latent variable modelling software. Mediation was tested on SPSS using linear regression to explain the relationship between environmental attitude and green purchasing behaviour.

The questionnaire was divided into three sections, the first being a filter question, followed by classification questions, and lastly, a scale section. The scale section consisted of questions measuring the constructs of the study, namely green purchasing behaviour, interpersonal influence, environmental knowledge, altruism, and environmental attitude.

The section measuring the constructs of the study made use of a Likert scale, which used five categories anchored by $1=$ Strongly Agree and $5=$ Strongly Disagree. The use of an odd number of categories allowed participants to have neutral responses [45]. The category descriptions for the questions measuring green purchasing behaviour, interpersonal influence, environmental knowledge, altruism, and environmental attitude were adapted from the study by [5], while questions measuring environmental knowledge and environmental attitude were adapted from the study by [30].

\section{Results}

There was a disproportionate representation of male and female respondents, being $71.4 \%$ female and $28.6 \%$ male. This was also the case in a similar study by [56], which investigated the moderating effect of gender on green purchase intention, with $74.8 \%$ of the 195 survey responses being female and $25.1 \%$ male.

The monthly income levels of respondents varied, with the majority earning R2 000-R7 999 a month, with a valid percentage of $43.6 \%$. A total of $12 \%$ of the respondents indicated that they had a monthly income level of R0-R1 999.

The second most common income bracket was R8 000-R16 999, with a valid percentage of 18.8\%. The income brackets of R17 000-R33 999 and R60 000 and above had valid percentages of $9.8 \%$ and $9 \%$ respectively. The least represented monthly income bracket was R34 000-R59 999 with a valid percentage of $6.8 \%$.

\subsection{Reliability and Validity}

The model reliability can be divided into internal consistency reliability and indicator reliability.

Internal consistency requires the analysis of the Cronbach's Alpha, which should be greater than 0.7, as well as the analysis of composite reliability, which should be greater than 0.8 . The construct reliability and validity presented in Table 1 below indicate that all the Cronbach Alpha scores were greater than 0.7, except for altruism with a value of 
0.69 , but this can be rounded up to 0.7 . In addition, all the composite reliability scores are greater than 0.8 . Therefore, this model can be said to have internal consistency reliability.

Table 1. Construct reliability and validity.

\begin{tabular}{cccc}
\hline & Cronbach's Alpha & $\begin{array}{c}\text { Composite } \\
\text { Reliability }\end{array}$ & $\begin{array}{c}\text { Average Variance } \\
\text { Extracted (AVE) }\end{array}$ \\
\hline Altruism & 0.694 & 0.863 & 0.760 \\
\hline Environmental Attitude & 0.842 & 0.888 & 0.616 \\
\hline Environmental Knowledge & 0.814 & 0.867 & 0.568 \\
\hline Green Purchasing Behaviour & 0.711 & 0.840 & 0.645 \\
\hline Interpersonal Influence & 0.838 & 0.891 & 0.671 \\
\hline
\end{tabular}

The model validity consists of convergent and discriminant validity. Convergent validity requires the average variance extracted (AVE) scores to be greater than 0.5 . The construct reliability and validity presented in Table 1 show that all AVE scores are greater than 0.5 , with altruism at 0.7 , environmental attitude, interpersonal influence, and green purchasing behaviour all having scores of over 0.6 , and environmental knowledge having an AVE score of 0.57. It can be concluded that the model has convergent validity.

Indicator reliability requires checking the model's outer loadings, which should be greater than 0.7 (or, if negative, the squares of the outer loadings should be greater than 0.5). The scores of the outer loadings in Table 2 are all positive. In addition, all scores were greater than 0.7 except for environmental attitude item 4 (EA4), environmental knowledge item 3 (EK3), and green purchasing behaviour item 3 (GP3), which all had values of 0.6.

Table 2. Outer loadings.

\begin{tabular}{|c|c|c|c|c|c|}
\hline & Altruism & $\begin{array}{c}\text { Environmental } \\
\text { Attitude }\end{array}$ & $\begin{array}{c}\text { Environmental } \\
\text { Knowledge }\end{array}$ & $\begin{array}{c}\text { Green Purchasing } \\
\text { Behaviour }\end{array}$ & $\begin{array}{c}\text { Interpersonal } \\
\text { Influence }\end{array}$ \\
\hline A1 & 0.819 & & & & \\
\hline $\mathrm{A} 2$ & 0.922 & & & & \\
\hline EA1 & & 0.795 & & & \\
\hline EA2 & & 0.773 & & & \\
\hline EA3 & & 0.907 & & & \\
\hline EA4 & & 0.608 & & & \\
\hline EA5 & & 0.811 & & & \\
\hline EK1 & & & 0.802 & & \\
\hline EK2 & & & 0.814 & & \\
\hline EK3 & & & 0.640 & & \\
\hline EK4 & & & 0.756 & & \\
\hline EK5 & & & 0.744 & & \\
\hline GP1 & & & & 0.895 & \\
\hline GP2 & & & & 0.904 & \\
\hline GP3 & & & & 0.605 & \\
\hline II1 & & & & & 0.811 \\
\hline II2 & & & & & 0.777 \\
\hline II3 & & & & & 0.838 \\
\hline II4 & & & & & 0.848 \\
\hline
\end{tabular}


As seen in Table 2, these items were only fractionally below the threshold, however, the model can be said to have indicator reliability. Additionally, as the model has both internal consistency reliability and indicator reliability, the model can be said to be reliable.

\subsection{Hypothesis Testing and Inferential Statistics}

Interpersonal influence has a significant positive effect on consumers' environmental attitude with regard to compostable coffee pods.

At the $5 \%$ level of significance with a $p$-value of 0.04 and a t-stat of 2.01 . It can therefore be concluded as shown in Table 3 that interpersonal influence does have a significant positive effect on consumers' environmental attitude with regard to compostable coffee pods.

Table 3. Mean, STDEV, $t$-Values, $p$-Values.

\begin{tabular}{|c|c|c|c|c|c|}
\hline & $\begin{array}{l}\text { Original } \\
\text { Sample }\end{array}$ & $\begin{array}{c}\text { Sample } \\
\text { Mean }\end{array}$ & $\begin{array}{l}\text { Standard } \\
\text { Deviation }\end{array}$ & T Statistics & $p$ Values \\
\hline Altruism $\geq$ Environmental Attitude & 0.569 & 0.535 & 0.128 & 4.427 & 0.000 \\
\hline Altruism $\geq$ Green Purchasing Behaviour & 0.255 & 0.246 & 0.070 & 3.630 & 0.000 \\
\hline Environmental Attitude $\geq$ Green Purchasing Behaviour & 0.448 & 0.458 & 0.063 & 7.119 & 0.000 \\
\hline Environmental Knowledge $\geq$ Environmental Attitude _ & 0.093 & 0.121 & 0.076 & 1.224 & 0.222 \\
\hline Environmental Knowledge $\geq$ Green Purchasing Behaviour & 0.042 & 0.057 & 0.038 & 1.096 & 0.274 \\
\hline Interpersonal Influence $\geq$ Environmental Attitude _ & 0.138 & 0.153 & 0.069 & 2.012 & 0.045 \\
\hline Interpersonal Influence $\geq$ Green Purchasing Behaviour & 0.061 & 0.065 & 0.033 & 1.864 & 0.063 \\
\hline
\end{tabular}

Altruistic values have a significant positive effect on consumers' environmental attitude with regard to compostable coffee pods.

As seen in Table 3, at the $5 \%$ level of significance with a $p$-value of 0.00 and a t-stat of 4.43. It can therefore be concluded that altruistic values do have a significant positive effect on environmental attitude with regard to compostable coffee pods.

Environmental knowledge has a significant positive effect on consumers' environmental attitude with regard to compostable coffee pods.

At the $5 \%$ level of significance with a $p$-value of 0.22 and a $t$-stat of 1.22 . As shown in Table 3, it can therefore be concluded that environmental knowledge does not have a significant positive effect on consumers' environmental attitude with regard to compostable coffee pods.

Environmental attitude has a significant positive effect on consumers' green purchasing behaviour towards compostable coffee pods.

At the $5 \%$ level of significance with a $p$-value of 0.00 and a t-stat of 7.12. It can therefore be concluded as seen in Table 3 that environmental attitude does have a significant positive effect on consumers' green purchasing behaviour towards compostable coffee pods.

Thus, all relationships in the model are significant and can be considered suitably influential in the model except for the relationship between environmental knowledge and environmental attitude. All the relationships in the model are positive.

\subsection{Mediation Analysis}

The first mediation analysis aimed to test if the demographic variable of gender mediates the relationship between environmental attitude and green purchasing behaviour. When analysing the results in Table 4, it was found that not all the relationships analysed in the model were significant, which proves that there was no mediation present in the model. Therefore, it can be concluded that gender does not mediate the relationship between environmental attitude and green purchasing behaviour. 
Table 4. Mediation results for gender.

\begin{tabular}{cccc}
\hline Path & Independent Variable & Standardised Coefficients Beta & Sig. \\
\hline A & Environmental Attitude & -0.145 & 0.095 \\
B & Gender & -0.139 & 0.111 \\
\hline C & Environmental Attitude & 0.426 & 0.000 \\
\hline \multirow{2}{*}{ All } & Environmental Attitude & 0.415 & 0.000 \\
& Gender & -0.079 & 0.326 \\
\hline
\end{tabular}

The second mediation analysis aimed to test if the demographic variable of income level mediates the relationship between environmental attitude and green purchasing behaviour. The results of the mediation test can be found in Table 5 below.

Table 5. Mediation results for income.

\begin{tabular}{cccc}
\hline Path & Independent Variable & Standardised CoefficientsBeta & Sig. \\
\hline D & Environmental Attitude & 0.280 & 0.036 \\
\hline E & Income Level & -0.175 & 0.044 \\
\hline F & Environmental Attitude & 0.426 & 0.000 \\
All & Environmental Attitude & 0.443 & 0.000 \\
& Income Level & -0.210 & 0.008 \\
\hline
\end{tabular}

As the paths were proven to be significant, it can be concluded that there is a significant relationship between the independent variable, the mediator, and the dependent variable in this study. The final regression model (all paths) was used to test if there is a linear relationship between the variables. At the $5 \%$ level of significance ( $p$-value $=0.00 \& 0.01$ ) Therefore, all the relationships are significant, which proves that there is mediation present in the model. In addition, it was found that income level partially mediates the relationship between environmental attitude and green purchasing behaviour.

\section{Discussion}

This study investigated the factors that influence consumers' green purchasing behaviour towards compostable coffee pods in South Africa, having identified through a literature review the opportunity for this further research. The research and statistical analysis produced several significant findings that provide key insights into the green purchasing behaviour of South African citizens.

To address the primary objective of the study, the research needed to determine which factors influence green purchasing behaviour with regard to compostable coffee pods. In summary, the findings derived from the statistical analysis concluded that interpersonal influence and altruistic values have a significant positive influence on environmental attitude and that environmental attitude has a significant positive effect on green purchasing behaviour.

The finding that pro-environmental attitude has a significant positive effect on green purchasing behaviour supports the findings of [38-40]. From this, it can be inferred that consumers who hold a favourable environmental attitude are more inclined to act/behave in a pro-environmental way. As a favourable attitude towards compostable packaging is a pro-environmental attitude, it can be inferred that consumers who have a favourable attitude towards compostable packaging are more inclined to participate in green purchasing behaviour.

The findings derived from the statistical analysis that concluded that interpersonal influence has a significant positive influence on pro-environmental attitude support the findings of $[26,27,37]$. Therefore, based on this finding derived from the structural equation modelling, it can be inferred that consumers' attitudes towards compostable coffee pods 
are influenced by social norms and peer groups and that consumers are motivated to buy green products such as compostable coffee pods to portray a positive image of themselves.

Additionally, as noted above, altruistic values have a significant positive influence on environmental attitude, and this finding is in accordance with those of $[7,30,31]$. This implies that consumers who have an awareness of harmful consequences to others take responsibility for changing the detrimental environment condition and are shown to possess a positive environmental attitude.

It was found that no significant relationship was observed between environmental knowledge and environmental attitude, however. These findings support those of [36,37], which concluded that environmental knowledge does not have a significant influence on environmental attitude.

To assess the study's secondary objectives, the research needed to determine if gender and income level mediate the relationship between environmental attitude and green purchasing behaviour towards compostable coffee pods.

From the meditation tests, it can be concluded that gender does not mediate the relationship between environmental attitude and green purchasing behaviour. This implies that gender does not change the strength of the relationship between environmental attitudes and green purchasing behaviour. This finding is contradictory to the findings of [43], who concluded that gender strengthened the relationship between green labelling and green purchasing behaviour.

The results from the second mediation tests revealed that income level partially mediates the relationship between environmental attitude and green purchasing behaviour, however, supporting the findings of [53]. This indicates that when consumers have higher levels of income, they are more likely to participate in green purchasing behaviour where they have positive environmental attitudes towards the product.

\section{Conclusions}

This research paper informs marketing practitioners, managers, and policy makers about the key predictors of green consumerism and green purchasing behaviour among South African consumers. The understanding of green purchasing behaviour will enable marketers to tailor their product offerings and formulate marketing strategies that encourage green buying behaviour and awareness about the environment, in this case within the coffee pod industry and with regard to compostable coffee pods.

The finding that interpersonal influence positively influences consumers' environmental attitude with regard to compostable coffee pods provides marketers of green products with a useful insight into how to improve communication effectiveness of their green message and green marketing campaigns. For instance, they should take advantage of the persuasive influence of important referents such as family members, peers, and friends and should feature relevant reference group appeals in their marketing campaigns. In addition, South African consumers should be effectively targeted in areas where they congregate to positively alter their social and interpersonal influence. Finally, green marketers should effectively communicate the environmental benefits of a product broadly within society, as this may strongly influence the individual intention towards green products due to the persuasive influence of a social group.

The study's conclusion that altruistic values positively influence consumers' environmental attitude towards compostable coffee pods suggests that South African consumers have a genuine care for the environment, offering green marketers the opportunity to target the values of these consumers. The relative importance of altruism in predicting green purchasing behaviour of compostable coffee pods suggests that marketers should be explicit in the link between their environmental strategies and beneficial outcomes, revealing how people generally are better off as a result.

Marketers should therefore adopt dual strategies of bringing about societal change through educating consumers about the environmental crisis at hand. In addition, mar- 
keters of green products such as compostable coffee pods need to emphasise that the role of consumers is pivotal in preserving the environment.

This study concluded that environmental attitude positively influences green purchasing behaviour with regard to compostable coffee pods and that environmental attitude is itself positively influenced by interpersonal influences and altruistic values of consumers. In view of this, marketers should effectively communicate their message and emphasise the environmental benefits of the product, which, in turn, may strongly influence the attitudes of consumers. Therefore, it is of primary importance that marketers foreground the benefit of purchasing green products in order to change consumer perceptions in a positive way. Developing positive beliefs about green products could, perhaps, be accomplished through green promotional materials and green advertisements that appeal to consumer rationality and emotions. Based on this study's research, top-level managers and marketers should aim to increase the positive environmental attitudes towards their green products in order to facilitate the likelihood of green purchasing behaviour.

Lastly, as income level was found to moderate the relationship between environmental attitude and green purchasing behaviour, marketers of green products should identify the segmented groups with a focus on income level in order to develop effective branding, design, and product pricing that will appeal to these groups. In addition, it is recommended that companies and green marketers improve the perception of the cost-benefit link for pro-environmental behaviour. Companies that are developing green marketing activities need to pursue efforts that will get their potential consumers to perceive specific benefits that arise from green purchasing behaviour and pro-environmental behaviour.

As income level moderates the relationship between environmental attitude and green purchasing behaviour, companies' business strategies need to take into account that in order to compete in the marketplace, firms need to offer comparable product benefits and standards at the competitive price categories in the market. This can be achieved through the refinement of product processes as well as effectively employing technology to create lower cost-based production processes.

\section{Limitations and Future Research}

Several limitations were found when conducting this study, which, if addressed, would increase the accuracy and reliability of results.

One limitation of the study is that the expected sample size of 200 respondents was not attained due to time constraints, and this resulted in a smaller sample size of 133 respondents being obtained. As the expected sample size could not be obtained, future research should obtain a larger sample size in order to gain more accurate results as well allow researchers to draw more in-depth conclusions.

The disproportionately high representation of female respondents compared to male is another limitation of the study. Future research could focus on obtaining a more even spread of respondents with regard to gender when testing this demographic variable as a mediator. In addition, the use of a non-probability sampling technique created a risk that the sample may not be representative of the larger target population [45].

Lastly, a conceptual limitation of this study is that the model used to perform structural equation modelling only focused on four constructs and excluded many. Therefore, future studies should make use of more constructs that influence green purchasing behaviour in the coffee pod industry as well as other measurement models relating to this. The framework of interpersonal influence, altruism, environmental awareness, and environmental attitude has limitations. Future studies should not only look at the packaging but include the content of coffee pods.

Although there were several limitations in this study, it was still possible to achieve the required results and relevant insights to effectively answer the research questions as well as help marketing managers better understand the factors that influence green purchasing behaviour with regard to compostable coffee pods. Therefore, within the context of green marketing and the conscious consumer, this study can be used as a basis for future research. 
Author Contributions: Conceptualisation, S.D.; methodology, R.V.; software, R.V.; validation, S.D. and R.V.; formal analysis, R.V.; investigation, R.V.; resources, S.D. and R.V.; writing-original draft preparation, R.V.; writing-review and editing, S.D.; visualisation, R.V.; supervision, S.D.; project administration, S.D.; funding acquisition, S.D. All authors have read and agreed to the published version of the manuscript.

Funding: This research was funded by the University of Cape Town, School of Management studies.

Institutional Review Board Statement: The study was conducted according to the guidelines of the University of Cape Town, and approved by the School of Management Studies Ethics Committee of University of Cape Town (protocol code MS_2020_VSSREB and 16 July 2020).

Informed Consent Statement: Informed consent was obtained from all subjects involved in the study.

Data Availability Statement: Data are available upon request.

Conflicts of Interest: The authors declare no conflict of interest.

\section{References}

1. Lanfranchi, M.; Giannetto, C.; Dimitrova, V. Evolutionary aspects of coffee consumers' buying habits: Results of a sample survey. Bulg. J. Agric. Sci. 2016, 22, 705-712.

2. Abuabara, L.; Paucar-Caceres, A.; Burrowes-Cromwell, T. Consumers' values and behaviour in the Brazilian coffee-in-capsules market: Promoting circular economy. Int. J. Prod. Res. 2019, 57, 7269-7288. [CrossRef]

3. Van der Merwe, K.; Maree, T. The behavioural intentions of specialty coffee consumers in South Africa. Int. J. Consum. Stud. 2016, 40, 501-508. [CrossRef]

4. Chen, M.F. The impacts of perceived moral obligation and sustainability self-identity on sustainability development: A theory of planned behavior purchase intention model of sustainability-labelled coffee and the moderating effect of climate change scepticism. Bus. Strategy Environ. 2020, 29, 2404-2417. [CrossRef]

5. Shao, J.; Ünal, E. What do consumers value more in green purchasing? Assessing the sustainability practices from the demand side of business. J. Clean. Prod. 2019, 209, 1473-1483. [CrossRef]

6. Panda, T.K.; Kumar, A.; Jakhar, S.; Luthra, S.; Garza-Reyes, J.A.; Kazancoglu, I.; Nayak, S.S. Social and environmental sustainability model on consumers' altruism, green purchase intention, green brand loyalty and evangelism. J. Clean. Prod. 2020, $243,118575$. [CrossRef]

7. Yadav, R.; Pathak, G.S. Young consumers' intention towards buying green products in a developing nation: Extending the theory of planned behavior. J. Clean. Prod. 2016, 135, 732-739. [CrossRef]

8. Vergragt, P.J. Transitions to sustainable consumption and production in cities. J. Clean. Prod. 2016, 134, 1-12. [CrossRef]

9. Balderjahn, I.; Peyer, M.; Seegebarth, B.; Wiedmann, K.P.; Weber, A. The many faces of sustainability-conscious consumers: A category-independent typology. J. Bus. Res. 2018, 91, 83-93. [CrossRef]

10. Huang, M.H.; Rust, R.T. Sustainability and consumption. J. Acad. Mark. Sci. 2011, 39, 40-54. [CrossRef]

11. Hojnik, J.; Ruzzier, M.; Konečnik Ruzzier, M. Transition towards sustainability: Adoption of eco-products among consumers. Sustainability 2019, 11, 4308. [CrossRef]

12. Van Herpen, E.; van Nierop, E.; Sloot, L. The relationship between in-store marketing and observed sales for organic versus fair trade products. Mark. Lett. 2012, 23, 293-308. [CrossRef]

13. Scott, L.; Vigar-Ellis, D. Consumer understanding, perceptions and behaviours with regard to environmentally friendly packaging in a developing nation. Int. J. Consum. Stud. 2014, 38, 642-649. [CrossRef]

14. Uddin, S.; Khan, M. Young consumer's green purchasing behavior: Opportunities for green marketing. J. Glob. Mark. 2018, 31, 270-281. [CrossRef]

15. Busse, M.; Menzel, S. The role of perceived socio-spatial distance in adolescents' willingness to engage in pro-environmental behaviour. J. Environ. Psychol. 2014, 40, 412-420. [CrossRef]

16. Guéguen, N.; Stefan, J. Green altruism: Short immersion in natural green environments and helping behavior. Environ. Behav. 2016, 48, 324-342. [CrossRef]

17. Hughner, R.S.; McDonagh, P.; Prothero, A.; Shultz, C.J.; Stanton, J. Who are organic food consumers? A compilation and review of why people purchase organic food. J. Consum. Behav. 2007, 6, 94-110. [CrossRef]

18. Geissdoerfer, M.; Saveget, P.; Bocken, N.; Hultink, E.J. A circular economy-A new sustainability paradigm? J. Clean. Prod. 2017, 143, 757-768. [CrossRef]

19. Huysman, S.; De Schaepmeester, J.; Ragaert, K.; De Wulf, J. Performance indicators for a circular economy: A case study on post-industrial plastic. Resour. Conserv. Recycl. 2017, 120, 46-54. [CrossRef]

20. Kalmykova, Y.; Sadagopan, M.; Rosado, L. Circular economy-From review of theories and practices to development of implementation tools. Resour. Conserv. Recycl. 2018, 135, 190-201. [CrossRef] 
21. Li, J. Comparative Life Cycle Assessment of Single-Serve Coffee Packaging in Ontario. Master's Thesis, University of Waterloo, Waterloo, ON, Canada, 2017. Available online: https:/ / uwspace.uwaterloo.ca/bitstream/handle/10012/12860/Li_Jingxi.pdf? sequ (accessed on 12 February 2020).

22. Humbert, S.; Loerincik, Y.; Rossi, V.; Margni, M.; Jolliet, O. Life cycle assessment of spray dried soluble coffee and comparison with alternatives (drip filter and capsule espresso). J. Clean. Prod. 2009, 17, 1351-1358. [CrossRef]

23. Charlebois, S.; Uys, P. The Compostable Coffee Pod: Is PürPod100 tm the Best Thing Since Sliced Bread? A Case Study on Club Coffee. Res. Appl. Econ. 2016, 8, 49-74. [CrossRef]

24. Kauffmann, H.; Panni, M.; Orphanidou, Y. Factors affecting consumers' green purchasing behavior: An Integrated Conceptual Framework. Amfiteatru Econ. J. 2012, 14, 50-69.

25. Mourali, M.; Laroche, M.; Pons, F. Individualistic orientation and consumer susceptibility to interpersonal influence. J. Serv. Mark. 2005, 19, 164-173. [CrossRef]

26. Cheah, I.; Phau, I. Attitudes towards environmentally friendly products: The influence of ecoliteracy, interpersonal influence and value orientation. Mark. Intell. Plan. 2011, 29, 452-472. [CrossRef]

27. Muzaffar, N. Developing an extended model of theory of planned behavior to explore green purchase behavior of Pakistani consumers. Am. J. Bus. Manag. 2015, 4, 85-101. [CrossRef]

28. Khare, A. Consumers' susceptibility to interpersonal influence as a determining factor of ecologically conscious behaviour. Mark. Intell. Plan. 2014, 32, 2-20. [CrossRef]

29. Albayrak, T.; Caber, M.; Moutinho, L.; Herstein, R. The influence of skepticism on green purchase behavior. Int. J. Bus. Soc. Sci. 2011, 2, 189-197.

30. Mostafa, M. Antecedents of Egyptian consumers' green purchase intentions. J. Int. Consum. Mark. 2006, 19, 97-126. [CrossRef]

31. Trivedi, R.; Patel, J.; Acharya, N. Causality analysis of media influence on environmental attitude, intention and behaviors leading to green purchasing. J. Clean. Prod. 2018, 196, 11-22. [CrossRef]

32. Polonsky, M.J. Transformative green marketing: Impediments and opportunities. J. Bus. Res. 2011, 64, 1311-1319. [CrossRef]

33. Kaiser, F.G.; Gutscher, H. The proposition of a general version of the theory of planned behavior: Predicting ecological behavior. J. Appl. Soc. Psychol. 2003, 33, 586-603. [CrossRef]

34. Chan, K. Market segmentation of green consumers in Hong Kong. J. Int. Consum. Mark. 2000, 12, 7-24. [CrossRef]

35. Vicente-Molina, M.; Fernández-Sáinz, A.; Izagirre-Olaizola, J. Environmental knowledge and other variables affecting proenvironmental behaviour: Comparison of university students from emerging and advanced countries. J. Clean. Prod. 2013, 61, 130-138. [CrossRef]

36. Laroche, M.; Bergeron, J.; Barbaro-Forleo, G. Targeting consumers who are willing to pay more for environmentally friendly products. J. Consum. Mark. 2001, 18, 503-520. [CrossRef]

37. Kollmuss, A.; Agyeman, J. Mind the Gap: Why do people act environmentally and what are the barriers to pro-environmental behaviour? Environ. Educ. Res. 2002, 8, 239-260. [CrossRef]

38. Chen, M.; Tung, P. Developing an extended Theory of Planned Behavior model to predict consumers' intention to visit green hotels. Int. J. Hosp. Manag. 2014, 36, 221-230. [CrossRef]

39. Prete, M.; Piper, L.; Rizzo, C.; Pino, G.; Capestro, M.; Mileti, A.; Pichierri, M.; Amatulli, C.; Peluso, A.; Guido, G. Determinants of Southern Italian households' intention to adopt energy efficiency measures in residential buildings. J. Clean. Prod. 2017, 153, 83-91. [CrossRef]

40. Perrea, T.; Grunert, K.G.; Krystallis, A.; Zhou, Y.; Huang, G.; Hue, Y. Testing and validation of a hierarchical values-attitudes model in the context of green food in China. Asia Pac. J. Mark. Logist. 2014, 26, 296-314. [CrossRef]

41. Schwepker, C.; Cornwell, T. An examination of ecologically concerned consumers and their intention to purchase ecologically packaged products. J. Public Policy Mark. 1991, 10, 77-101. [CrossRef]

42. Prakash, G.; Pathak, P. Intention to buy eco-friendly packaged products among young consumers of India: A study on developing nation. J. Clean. Prod. 2017, 141, 385-393. [CrossRef]

43. Chekima, B.; Syed-Khalid-Wafa, S.; Igau, O.; Chekima, S.; Sondoh, S. Examining green consumerism motivational drivers: Does premium price and demographics matter to green purchasing? J. Clean. Prod. 2016, 112, 3436-3450. [CrossRef]

44. Panni, M. The Effect of Consumerism towards Customer Attitudinal Behaviour in Food Industry in Malaysia. Master's Thesis, Multimedia University, Malacca, Malaysia, 2006.

45. Malhotra, N.K. Marketing Research an Applied Orientation, 6th ed.; Pearson: Upper Saddle River, NJ, USA, 2010.

46. Kalamas, M.; Cleveland, M.; Laroche, M. Pro-environmental behaviors for thee but not for me: Green giants, green Gods, and external environmental locus of control. J. Bus. Res. 2014, 67, 12-22. [CrossRef]

47. Matthes, J.; Wonneberger, A.; Schmuck, D. Consumers' green involvement and the persuasive effects of emotional versus functional ads. J. Bus. Res. 2014, 67, 1885-1893. [CrossRef]

48. Zelezny, L.; Chua, P.; Aldrich, C. New Ways of Thinking about Environmentalism: Elaborating on Gender Differences in Environmentalism. J. Soc. Issues 2000, 56, 443-457. [CrossRef]

49. Dagher, G.; Itani, O.; Kassar, A. The impact of environment concern and attitude on green purchasing behavior: Gender as the moderator. Contemp. Manag. Res. 2015, 11, 179-206. [CrossRef]

50. Davidson, D.; Freudenburg, W. Gender and environmental risk concerns. Environ. Behav. 1996, 28, 302-339. [CrossRef] 
51. Hayes, B. Gender, scientific knowledge, and attitudes toward the environment: A cross-national analysis. Political Res. Q. 2001, 54, 657-671. [CrossRef]

52. Junaedi, S. The role of income level in green consumer behavior: Multigroup structural equation model analysis. In Proceedings of the International Conference on Business and Management, Phuket, Thailand, 6-7 September 2012; pp. 6-7.

53. Straughan, R.; Roberts, J.A. Environmental segmentation alternatives: A look at green consumer behavior in the new millennium. J. Consum. Mark. 1999, 16, 558-575. [CrossRef]

54. Bloom, D.; Sevilla, J. Willingness to pay for environmental quality: Testable empirical implications of the growth and environment literature: Comment. Contrib. Econ. Anal. Policy 2004, 3, 1320-1332. [CrossRef]

55. Perneger, T.; Courvoisier, D.; Hudelson, P.; Gayet-Ageron, A. Sample size for pre-tests of questionnaires. Qual. Life Res. 2014, 24, 147-151. [CrossRef] [PubMed]

56. Lasuin, C.; Yeun Ching, N. Factors Influencing green purchase intention among university students. Malays. J. Bus. Econ. 2014, 1, $1-14$. 